\title{
Article \\ Class Year Differences in Anthropometric and Fitness Measures in Division I Field Hockey Athletes Pre and Post Season
}

\author{
Kathleen A. Bieryla ${ }^{1, *}$, Jeremy A. Cook ${ }^{2}$ and Ryan C. Snyder ${ }^{3}$ \\ 1 Shiley School of Engineering, University of Portland, Portland, OR 97203, USA \\ 2 Department of Athletics, Bucknell University, Lewisburg, PA 17837, USA; jac059@bucknell.edu \\ 3 Department of Chemical Engineering, Bucknell University, Lewisburg, PA 17837, USA; rcs048@bucknell.edu \\ * Correspondence: bieryla@up.edu; Tel.: +1-503-943-7176
}

check for updates

Citation: Bieryla, K.A.; Cook, J.A.; Snyder, R.C. Class Year Differences in Anthropometric and Fitness Measures in Division I Field Hockey Athletes Pre and Post Season. Appl. Sci. 2021, 11, 8103. https://doi.org/ 10.3390/app11178103

Academic Editor: Mark King

Received: 23 June 2021

Accepted: 27 August 2021

Published: 31 August 2021

Publisher's Note: MDPI stays neutral with regard to jurisdictional claims in published maps and institutional affiliations.

Copyright: (c) 2021 by the authors. Licensee MDPI, Basel, Switzerland. This article is an open access article distributed under the terms and conditions of the Creative Commons Attribution (CC BY) license (https:/ / creativecommons.org/licenses/by/ $4.0 /)$.

\begin{abstract}
The purpose of this study was to investigate the way in which anthropometric and fitness measures vary by class year before and after a Division I female field hockey competitive season. Anthropometric (mass and percent body fat) and fitness measures (vertical jump and YoYo Intermittent Recovery Test 1 (Yo-Yo IR1) distance) were collected on 16 athletes (mean \pm SD: age $=19.5 \pm 0.9$ years) before and after a competitive season. Class year, based on the athlete's year in college, was used to group athletes in the study. Body mass, vertical jump height, and Yo-Yo IR1 distance all increased pre to post season $(p<0.05)$. First-year athletes had a significantly lower body mass, vertical jump height and Yo-Yo IR1 distance compared to other class years across the testing period $(p<0.05)$. Post season levels for first-years were lower than both pre and post season levels for sophomore or junior athletes. Team mean vertical jump increased $8.9 \%$, with all but two athletes improving. Team mean Yo-Yo IR1 distance increased 16.4\%. Athlete training over the course of the study was designed to improve on field playing performance and training was not directly select to improve measures in the study; therefore, the potential success of integrating fitness, speed, and strength development into technical training sessions is indicated. Coaches should be aware that first-year athletes may not be at the same level of conditioning as sophomores and juniors. Coaches should work specifically with the first-year athletes during the season to monitor their fitness levels.
\end{abstract}

Keywords: field sports; seasonal changes; Yo-Yo Intermittent Recovery Test 1; vertical jump; percent body fat; women

\section{Introduction}

Field hockey is a team sport that involves bouts of high speed running followed by time spent walking and jogging [1,2]. Games are played on an artificial turf surface and consist of two 35-min halves with a 10-min half time at the time of this study [3]. Internationally, field hockey is a more popular sport than in the United States and may be played by individuals as young as four years old. In the United States, youth field hockey leagues are less common. While research does exist at the international level for field hockey athletes [4-6], there is little research on collegiate field hockey athletes in the United States. Due to differences between international professional players and collegiate players, research is needed on collegiate athletes. The NCAA dictates rules for collegiate athletes that are different than a professional setting, restricting the number of hours athletes can have formalized practice each week and when practices may occur [7]. In the United States, female soccer has broader sport participation rates. Field hockey is similar to soccer, as there are 10 field players and a goalkeeper. Much research has examined anthropometric and fitness measures of collegiate female soccer athletes [8-11], but very little exists on collegiate female field hockey athletes. This may be due to the difference in number of women's Division I teams in the United States, with 335 soccer teams [12] compared to only 77 field hockey teams [13]. Additionally, while there are some similarities between field hockey and soccer, there are also critical differences that dictate the importance of field 
hockey specific research [3,14]. In soccer, there is an offside rule, while in field hockey there is not. Another difference is in player substitution. In collegiate soccer, during the first half, substituted players may not re-enter the game and during the second half substituted players may re-enter once. Additionally, soccer players must wait until the game is stopped to substitute. In field hockey, coaches can freely substitute players, without stoppage of the game, and there is no limit to the number of times a player can re-enter the field of play. Furthermore, soccer has a bigger field $\left(7525.28 \mathrm{~m}^{2}\right)$ compared to field hockey $\left(5027 \mathrm{~m}^{2}\right)$. Limited substitution and a larger field lead to soccer necessitating more endurance than field hockey, while field hockey players can use frequent substitutions to complete more sprints and recovery.

Only one study to the author's knowledge, has examined differences in anthropometric and fitness measures in collegiate women's field hockey athletes. In a group of Division II women's field hockey athletes, goalkeepers had a higher body mass and percent body fat compared to all other positions [15]. No difference was found in grip strength, height, or 50-yard dash time across positions. Since this study was completed, a rule change allowing players to self-start, which involves taking free hits to themselves, resulted in an increased pace of game play, since little time is needed to reset. Therefore, the characteristics of a field hockey team may have changed and new research is needed. Additionally, the current study examines the changes over the course of a season, compared to only one time point.

Understanding the level of fitness prior to a season can help coaches design training and conditioning for potential gains during the competitive season. This knowledge is of particular concern for first-year athletes that are coming from a high school program. High school conditioning can vary from team to team; therefore, first-year athletes may not be starting at the same fitness levels as each other. In a survey sent to Division I NCAA strength and conditioning coaches examining the readiness of first-year athletes, the researchers concluded "incoming college freshman athletes are not adequately prepared for the rigors of intercollegiate athletics [16]". First-year athletes are generally the youngest on the team and need time to mature physically. In Division I football players, it was noted that the largest gains in body mass and vertical jump and decrease in percent body fat occurred during the athlete's first-year [17]. One study examined differences between class years in women's Division I soccer and found no significant differences in height, mass, vertical jump, or distance in Yo-Yo Intermittent Recovery Test Levels 1 (Yo-Yo IR1) and 2 (Yo-Yo IR2) [18]. This study measured the athletes one time, during their off-season, and did not examine first-year athletes prior to the start of their competitive season. Awareness of how the athletes begin the season is critical. Annual testing can also inform coaches on how each cohort is progressing through years of training. A longitudinal study has been conducted tracking female Division I basketball, swimming, volleyball, soccer, and track athletes over the course of multiple seasons, but did not include field hockey athletes [19]. Female Division I basketball players increased bench press, squat, incline press and vertical jump from their first year to senior year [20]. No study has examined changes in anthropometric or fitness measures across a season for Division I field hockey athletes.

Fitness levels of athletes can vary by class year and it may be useful for coaches to understand those differences $[17,18,20-22]$. Testing of athletes prior to the season could determine whether incoming first-year athletes are physically fit for playing at the collegiate level. Currently, no study has examined differences in anthropometric and fitness levels, specifically, body mass, percent body fat, vertical jump, and Yo-Yo IR1 distance between class years in collegiate field hockey athletes. Therefore, the purpose of this study was to investigate how body mass, percent body fat, vertical jump, and Yo-Yo IR1 distance, vary between class years, and across a competitive season in a women's Division I field hockey team. It is hypothesized that first-year athletes will have a lower body mass, higher percent body fat, lower vertical jump height, and shorter Yo-Yo IR1 distance when compared to older athletes. It is also hypothesized that the vertical jump height and Yo-Yo IR1 distance will increase for all class years across the season. 


\section{Materials and Methods}

\subsection{Participant Characteristics}

The study was conducted on a NCAA Division I female field hockey team with 21 members. Inclusion criteria for the study was a field player (non-goalkeeper), 18 years or older at the beginning of the study, injury free for at least half the season, and completion of data collection both pre and post season. Of the 21 athletes, five were removed for not fitting the inclusion criteria: three did not complete post season data collection, a fourth was not a field player, and one was under 18 years of age at the beginning of the study. Therefore, anthropometric and fitness measures were collected on 16 NCAA Division I female field hockey athletes from the same team (mean \pm SD: age $=19.5 \pm 0.9$ years; height $=166.4 \pm 6.3 \mathrm{~cm}$ ). All included study participants missed no more than one week of activity due to injury. The study was approved by the university's Institutional Review Board and written informed consent was obtained from all participants prior to data collection. Prospective participants in the study were given a presentation about the study along with a written explanation before any data collection occurred. Those prospective participants who returned signed informed consent forms were included in the study.

Class year was used to group athletes: first-year $(n=5$, age $=18.4 \pm 0.2$ years, height $=167.7 \pm 5.4 \mathrm{~cm})$, sophomore $(n=4$, age $=19.6 \pm 0.3$ years, height $=167.0 \pm 3.2 \mathrm{~cm})$, and junior $(n=7$, age $=20.3 \pm 0.3$ years, height $=165.1 \pm 8.5 \mathrm{~cm})$. The university involved in the study does not typically allow athletes to redshirt, except for medical reasons. No such specific medical cases were present for any members of the team in the fall 2017 semester; therefore, in the context of this study, all athletes described as a "first-years" were in their first year of college started after their senior year in high school, "sophomores" were in their second year of college, and "juniors" were in their third year of college.

\subsection{Experimental Procedures}

The athletes were tested in August 2017 at the beginning of the pre-season and again in November 2017 after the end of the competitive season. The time between pre and post measures was 13 weeks. The first two weeks took place before the start of classes and the remaining 11 weeks took place during the academic year which included 10 regular season weeks and one post season week, culminating with the league tournament. There were two scrimmages, i.e., games played prior to the first regular season game that do not count towards the team's win-loss record, in the pre season, 18 games in the regular season, and two games in the league tournament. Each week included both field training and weight training. A typical week included two hours of weight training and one or two competitive games. Weight training was consistent with an in-season program prioritizing injury prevention over strength or explosive gains, using a combination of resistance and plyometric exercises. The program was periodized off the previous spring and summer, modulating every two weeks, with a performance peak at the end of October. The program was further monitored to compliment on-field conditioning and activities. Typically, weeks with one competitive game had approximately eight hours of field training while weeks with two competitive games had approximately six hours of field training. Field training consisted of hockey skill-based drills, small sided games and large coached games. Each of these were intentionally designed to mimic activity levels seen during a game. These were generally done in 6-7 min increments followed by a 3-4 min rest. All athletes completed the same amount of field training each week, with only game time differing between players for overall training exposure. For each game, the time spent on the field relative to the total game time, was calculated for each athlete and called percent playing time. The percentage of playing time for each game, for each athlete, was calculated from substitution sheets provided by the head coach. The individual game percent playing time was then averaged for the season.

This study used both anthropometric measures, body mass, and percent body fat, as well as fitness measures, vertical jump height, and Yo-Yo IR1 distance traveled. Mass was measured using a standard scale to the nearest $0.5 \mathrm{~kg}$, and height was measured 
using a stadiometer to the nearest $0.5 \mathrm{~cm}$, both without shoes. To measure height, athletes were instructed to stand with knees straight, arms at their sides, looking straight ahead. Percent body fat was measured using a Bod-eComm2 (Futrex Tech, Inc., Hagerstown, $\mathrm{MD}, \mathrm{USA}$ ) according to the manufacturers recommended procedures. The Bod-eComm2 uses near-infrared interactance (NIR) to measure percent body fat. A Light Wand was placed on the athlete's biceps and percent body fat was calculated from the manufacturer's pre-programmed regression equation. NIR was chosen due to its ease of use, in that it is noninvasive, portable, and requires no special restrictions for the subject [23]. The BodeComm2 uses the same technology as the Futrex-6100, which has been shown to be a valid method to estimate percent body fat in college-age women [24]. Test-retest measurements from one lab using the Futrex-6100/XL found a total error measurement of $0.704 \%$ and coefficient of variation of $3.62 \%$ [25]. Team members were encouraged to be well hydrated throughout the season, and no additional instructions regarding hydration were provided specifically around the time of anthropometric measurements. Additionally, no restriction was placed on eating, as the players needed to be ready for practice. The same protocol was followed for both pre and post season testing. Athletes wore athletic apparel during the anthropometric measurements and all anthropometric measurements were performed by the same two people: an assistant coach and a certified athletic trainer. Pre season anthropometric measures were taken the evening before the first pre season practice. Post season anthropometric measures were taken two to five days after the final competitive match, which was chosen based on student availability in coordination with their class and exam schedules.

A single Yo-Yo IR1 was performed on a turf hockey field [26,27]. Athletes completed repeated $2 \times 20 \mathrm{~m}$ shuttle runs at increasing speeds with a $10 \mathrm{~s}$ recovery time following each $2 \times 20 \mathrm{~m}$ shuttle. Athletes received a warning the first time they did not complete the run within the allotted time. Upon the second failure, the test was stopped and total distance ran was calculated. The Yo-Yo IR1 was shown to be reliable and correlated to high intensity running in both soccer and field hockey [27,28]. Athletes completed the pre and post season Yo-Yo IR1 as a group, administered by the team coach and assistant coaches. The pre season Yo-Yo IR1 was performed early morning on the first day of pre season practice, taking place before all other practice activities. The post season Yo-Yo IR1 test was performed three days after the final competitive match in the late afternoon, as this was the allowable practice time for the athletes during the academic year.

For the vertical jump test, athletes completed a countermovement jump. Athletes were instructed to begin upright with their feet shoulder width apart. Athletes swung their arms back to move to a semi squat position in preparation for the jump. Athletes jumped in the air, swinging their arms forward and above their head. The best of three of these countermovement jumps was used with $30 \mathrm{~s}$ of recovery between jumps. The jump height was measured as the difference in the standing reach height to the highest marker reached by a Vertec vertical jump tester, which provides data in $1.27 \mathrm{~cm}$ increments (JumpUSA, Sunnyvale, CA, USA). Vertical jump was selected as a metric for the field hockey athletes, as it is correlated to sprint and change of direction speeds [29]. This method has been shown to be valid in comparison to other vertical jump test methods [30]. The pre season and post season vertical jump tests were administered by the team strength and conditioning coach. The pre season vertical jump was performed in the morning, before any practice activities, three days after the Yo-Yo IR1 pre season test. The post season vertical jump was performed in the morning, scheduled around team class schedules, six days after the Yo-Yo IR1 post season test.

\subsection{Statistical Analysis}

A one-way ANOVA was used to determine any differences in playing time and height between class years. A two-way, repeated measure, mixed model ANOVA was used to determine the effects of session (pre and post season), class year (first year, sophomore, junior) and their interaction on body mass, percent body fat, vertical jump height, and 
Yo-Yo IR1 distance. In the event of a significant main effect or interaction, post-hoc Tukey HSD was conducted. The effect sizes, partial eta squared $\left(\eta_{p}{ }^{2}\right)$, were calculated and were considered small $\left(\eta_{p}{ }^{2}=0.01\right)$, medium $\left(\eta_{p}^{2}=0.06\right)$, and large $\left(\eta_{p}^{2}=0.14\right)[31,32]$. All statistical analyses were completed in JMP Pro 12 (Cary, NC) with significance set at $p<0.05$ for all tests.

\section{Results}

Percent playing time for each player is shown in Figure 1. There was a significant difference in percent playing time between the class years $\left(\mathrm{F}_{2,13}=6.128, p=0.013, \eta_{\mathrm{p}}{ }^{2}=0.485\right)$, with first-years having a significantly lower average percent playing time, $26.0 \pm 22.0 \%$, than sophomores at $63.8 \pm 5.7 \%(p=0.021)$, and juniors at $57.3 \pm 19.1 \%(p=0.028)$. There was no difference in height between the class years $\left(\mathrm{F}_{2,13}=0.236, p=0.793, \eta_{\mathrm{p}}{ }^{2}=0.035\right)$.

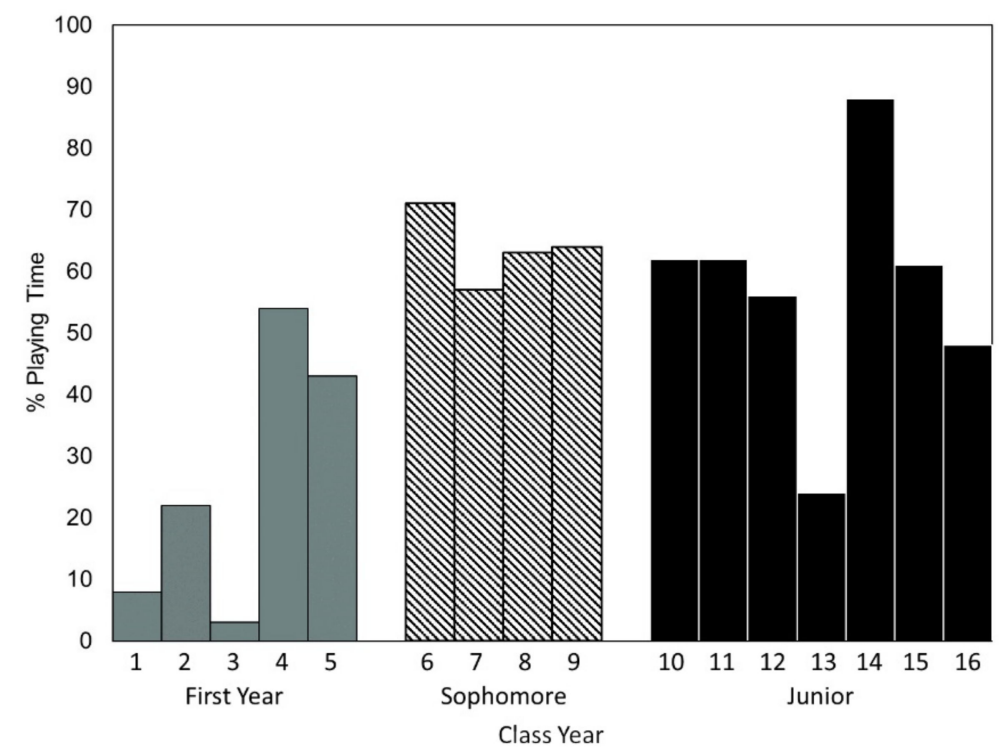

Figure 1. Percentage of total on field playing time for each athlete, grouped by class year.

Pre season and post season average values of body mass, percent body fat, vertical jump, and Yo-Yo IR1, for each class year are presented in Table 1. There was a significant main effect of session $\left(\mathrm{F}_{1,13}=9.640, p=0.008, \eta_{\mathrm{p}}{ }^{2}=0.426\right)$ and class year $\left(\mathrm{F}_{2,13}=92.950\right.$, $\left.p<0.001, \eta_{\mathrm{p}}{ }^{2}=0.935\right)$ and a significant interaction effect $\left(\mathrm{F}_{2,13}=4.074, p=0.042, \eta_{\mathrm{p}}{ }^{2}=0.385\right)$ on body mass (Table 1$)$. There was a significant main effect of class year $\left(\mathrm{F}_{2,13}=129.665\right.$, $\left.p<0.001, \eta_{\mathrm{p}}{ }^{2}=0.952\right)$, but no significant effect of session $\left(\mathrm{F}_{1,13}=3.755, p=0.075, \eta_{\mathrm{p}}{ }^{2}=0.224\right)$ or interaction $\left(\mathrm{F}_{2,13}=1.610, p=0.237, \eta_{\mathrm{p}}{ }^{2}=0.199\right)$ on percent body fat. First-year athletes started the pre season with a lower body mass and percent body fat than sophomores (body mass: $p<0.001$, percent body fat: $p<0.001$ ) and juniors (body mass: $p<0.001$, percent body fat: $p<0.001)$. Additionally, first-year athletes significantly increased their body mass pre to post season $(p=0.013)$. The average body mass gain for first-year athletes was $3.03 \mathrm{~kg}$, $0.33 \mathrm{~kg}$ for sophomores, and $0.58 \mathrm{~kg}$ for juniors from pre to post season. Although each first-year athlete increased their body mass over the season, and all but one increased their percent body fat, the average post season body mass and percent body fat for first-year athletes were still lower than both pre and post season averages of sophomores and juniors. The percent difference in average post season body mass was $9.3 \%$ for first-years compared to sophomores and was $4.3 \%$ for first-years compared to juniors. The percent difference in percent body fat post season was $14.7 \%$ for first-years compared to sophomores and was $13.3 \%$ for first-years compared to juniors. Four athletes had slight decreases in their body mass and percent body fat over the course of the season, with a maximum percent decrease of $2.9 \%$ for mass and $4.3 \%$ for body fat (Figure 2). Each of these players played more than $60 \%$ of the time. 
Table 1. Pre and post season data of anthropometric and fitness measures for first-year $(n=5)$, sophomore $(n=4)$, and junior $(n=7)$ athletes, in addition to team $(n=16)$ data. Mean \pm standard deviation reported.

\begin{tabular}{|c|c|c|c|c|c|c|c|c|}
\hline & \multicolumn{4}{|c|}{ Pre Season } & \multicolumn{4}{|c|}{ Post Season } \\
\hline & $\begin{array}{l}\text { First-Year } \\
\quad(n=5)\end{array}$ & $\begin{array}{l}\text { Sophomore } \\
\quad(n=4)\end{array}$ & $\begin{array}{l}\text { Junior } \\
(n=7)\end{array}$ & $\begin{array}{c}\text { Team } \\
(n=16)\end{array}$ & $\begin{array}{l}\text { First-Year } \\
\quad(n=5)\end{array}$ & $\begin{array}{l}\text { Sophomore } \\
\quad(n=4)\end{array}$ & $\begin{array}{l}\text { Junior } \\
(n=7)\end{array}$ & $\begin{array}{c}\text { Team } \\
(n=16)\end{array}$ \\
\hline Mass (kg) & $60.9 \pm 8.5$ & $69.7 \pm 2.3$ & $66.2 \pm 6.2$ & $65.4 \pm 6.9$ & $63.9 \pm 10.7$ & $70.1 \pm 2.8$ & $66.7 \pm 6.7$ & $66.7 \pm 7.5$ \\
\hline \% Body Fat & $18.0 \pm 2.2$ & $21.9 \pm 1.3$ & $21.3 \pm 2.8$ & $20.4 \pm 2.7$ & $18.9 \pm 2.9$ & $21.9 \pm 1.2$ & $21.6 \pm 2.9$ & $20.8 \pm 2.8$ \\
\hline Vertical Jump $(\mathrm{cm})$ & $39.4 \pm 5.3$ & $41.3 \pm 4.2$ & $41.0 \pm 2.0$ & $40.6 \pm 3.7$ & $43.2 \pm 7.6$ & $46.0 \pm 5.8$ & $43.9 \pm 3.7$ & $44.2 \pm 5.4$ \\
\hline Yo-Yo IR1 (m) & $744.0 \pm 222.0$ & $1250 \pm 210.1$ & $1062.9 \pm 284.6$ & $1010.0 \pm 307.6$ & $920.0 \pm 105.8$ & $1330.0 \pm 253.8$ & $1194.3 \pm 355.8$ & $1142.5 \pm 306.0$ \\
\hline
\end{tabular}
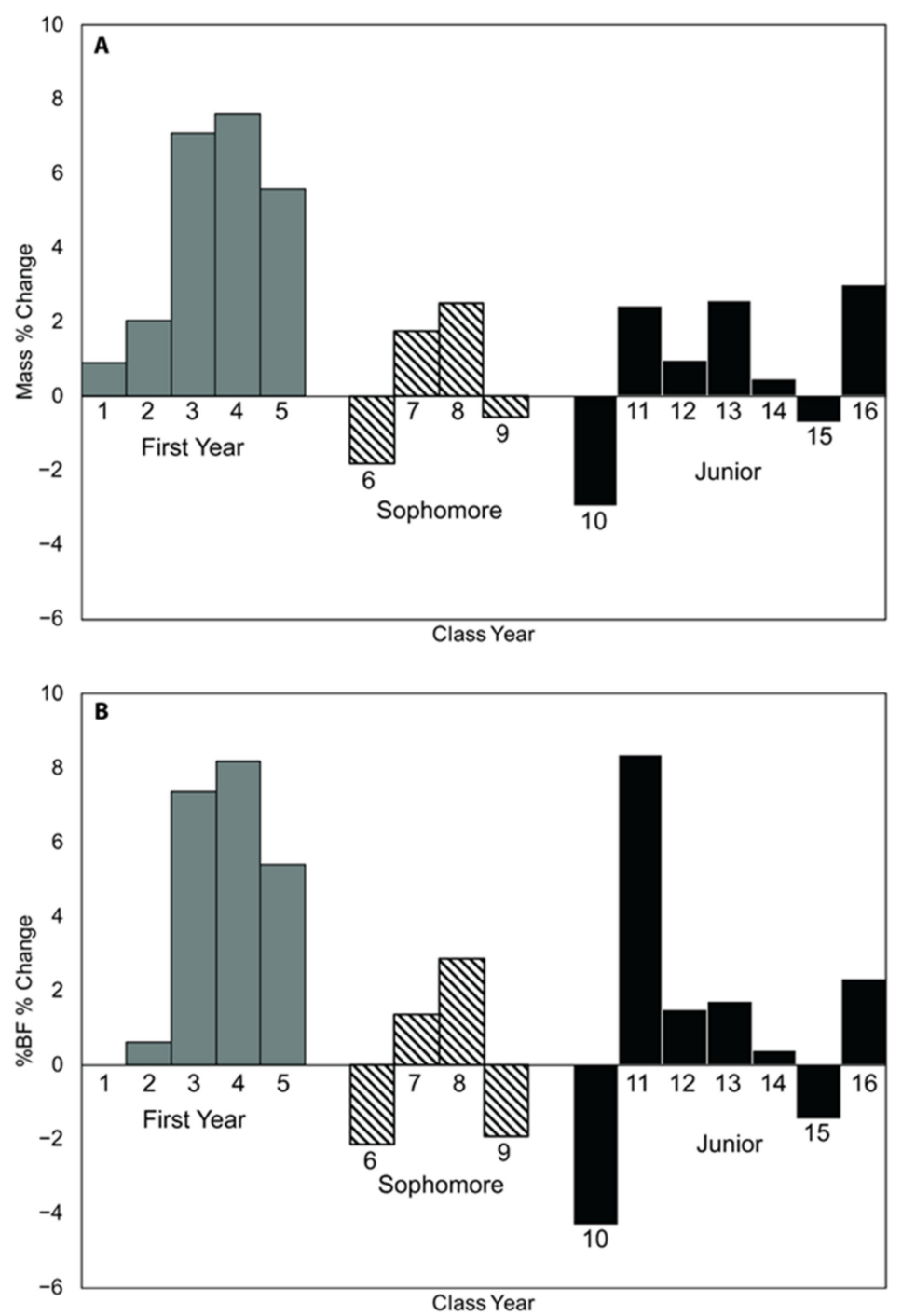

Figure 2. Percent change from pre season to post season for each individual player, grouped by class year for (A) mass and (B) percent body fat.

Vertical jump height for all athletes improved pre to post season an average of $8.9 \pm 7.0 \%\left(\mathrm{~F}_{1,13}=22.900, p<0.001, \eta_{\mathrm{p}}{ }^{2}=0.638\right)$. First-year athletes, on average, performed worse on the vertical jump during both the pre and post season compared to sophomores and juniors, though there was no significant main effect of class year $\left(\mathrm{F}_{2,13}=2.610, p=0.111\right.$, $\left.\eta_{\mathrm{p}}{ }^{2}=0.287\right)$ or interaction effect $\left(\mathrm{F}_{2,13}=0.463, p=0.639, \eta_{\mathrm{p}}{ }^{2}=0.067\right)$ on vertical jump. All but one athlete, a junior, improved or maintained their jump height post season. The largest gains were seen in the sophomores who increased an average of $11.5 \pm 6.4 \%$, compared to $9.2 \pm 4.5 \%$ for the first-years and $7.2 \pm 9.0 \%$ for the juniors (Figure $3 \mathrm{~A}$ ). The single largest percent change, $25.0 \%$, occurred in a junior athlete. This player also had the largest absolute increase in jump height, $10.2 \mathrm{~cm}$, where she went from having the fifth highest jump pre season to the third highest jump post season. 

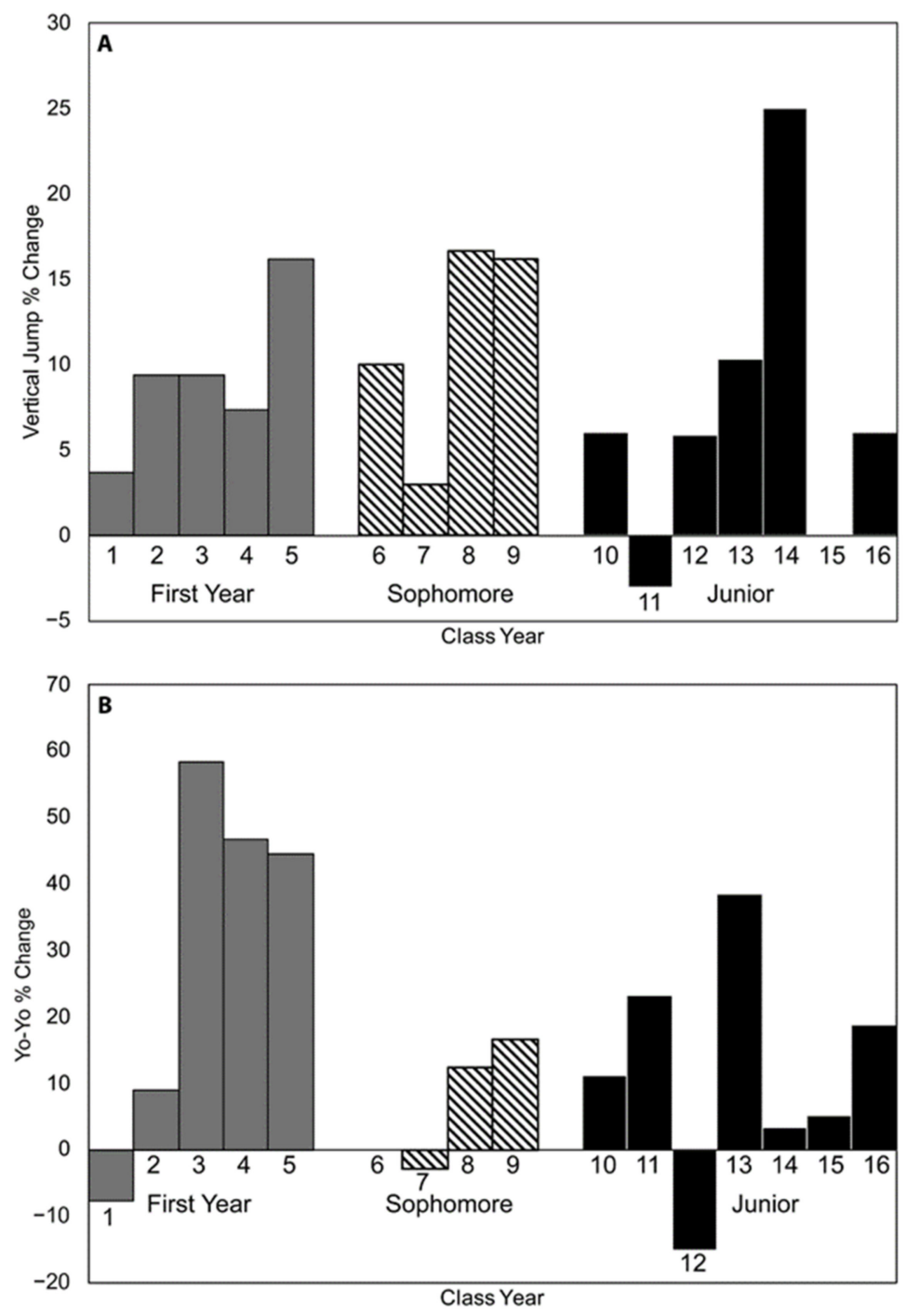

Figure 3. Percent change from pre season to post season for each individual player, grouped by class year for (A) vertical jump and (B) Yo-Yo IR1 distance.

There was a main effect of class year $\left(\mathrm{F}_{2,13}=38.961, p<0.001, \eta_{\mathrm{p}}=0.857\right)$ and session $\left(\mathrm{F}_{1,13}=9.860, p<0.008, \eta_{\mathrm{p}}{ }^{2}=0.431\right)$ on Yo-Yo IR1 distance. First-year athletes performed worse on the Yo-Yo IR1 compared to sophomores $(p<0.001)$ and juniors $(p<0.001)$. All but three athletes increased their Yo-Yo IR1 distance pre to post season (Figure 3B). Each of these players played less than $60 \%$ of the time. The largest gains were seen in the first-year athletes who increased an average of $30.2 \pm 28.0 \%$, compared to $12.2 \pm 16.9 \%$ for the juniors and $6.6 \pm 9.5 \%$ for the sophomores. The top three gains in percent change were seen in first-year athletes, due to the athletes starting at a lower initial distance. The single largest percent change, $58.3 \%$, was a first-year athlete who played the least, started with the lowest initial Yo-Yo IR1 distance, and ended the season with the second lowest Yo-Yo IR1 distance. There was no interaction effect $\left(\mathrm{F}_{2,13}=0.399, p=0.679, \eta_{\mathrm{p}}{ }^{2}=0.058\right)$ on Yo-Yo IR1 distance. The average power for all main effects was $81.6 \%$.

The data set is available online in Supplementary Materials.

\section{Discussion}

This study was the first to examine differences in anthropometric and fitness measures between class years in Division I female field hockey players. First-year athletes had lower values for the anthropometric measures, mass and percent body fat. First-year athletes also 
had lower vertical jump height and Yo-Yo IR1 distance in accordance with the hypothesis. Additionally, when averaged across all athletes, all measures increased pre to post season.

While mass and percent body fat, on average, increased slightly for all class years, the largest gains were seen in the first-year. First-years had the lowest average mass which is different from a study that examined differences in mass in Division I female soccer players [18]. Lockie et al. found that their redshirt athletes, who were equivalent in experience to the current study's first-years, were not different in mass from the next two grade levels [18]. It should be noted that the soccer measurements were recorded in February and March, three to four months after a competitive season, compared to the pre season data reported in this paper collected in August. Average field hockey mass post season was higher for all equivalent class years than the soccer players. The average mass increase for first-year field hockey athletes of $3.0 \mathrm{~kg}(4.6 \%)$ is slightly higher than the average mass increase for first-year college students. A meta-analysis conducted on 24 studies found a weighted mean of $1.75 \mathrm{~kg}$ increase in first-years' (both male and female) mass [33] while a second meta-analysis found an average of $1.34 \mathrm{~kg}$ increase in mass for female first-years [34]. The meta-analysis also suggests that the largest gains for mass occur in the first semester of the first-year [34]. Since the field hockey season occurs in the fall, which for first-year students is the first semester of their first year, the increase in mass seen in the first-year athletes may be a result of the combination of the first semester in college and athletic training.

First-year percent body fat was comparable to Division II field hockey players reported at $17.29 \pm 3.79 \%$ [15]. The sophomores and juniors, while having a higher percent body fat than the first-year athletes, were lower than elite English field hockey players $(23.0 \pm 1.9 \%)$ aged $22.7 \pm 2.8$ years [ 4 ] and regional Australian field hockey players $(24.8 \pm 0.7 \%)$ aged $19.4 \pm 1.0$ years [5]. While important to consider, direct comparisons to past studies with respect to percent body fat have many challenges. The method of calculating percent body fat was not consistent across all studies. The current study used NIR to measure percent body fat compared to standard calipers in the other studies. The game play is also different between the studies. As stated in the introduction, numerous NCAA rule changes have occurred since the study on Division II players, and international games have different rules from the NCAA. Due to different regulations (e.g., NCAA rules) and player expectations (students, non-students) the training environment also can be very different between levels of play, which cannot be controlled for when comparing results [7]. The degree to which player behavior off the field also can vary. In this study, the athletes had one large group meeting with a nutritionist. Additional individual coaching on nutrition was offered to each subject; however, they were not required to further engage with nutritional coaching and their nutritional activities were not tracked throughout the season. Similarly to body mass, the increase in percent body fat for first year athletes may be due to changes that occur during the first semester in college, such as change in diet, and differences in athletic training compared to sophomores and juniors.

Average vertical jump heights for this study, other than for pre season first-years, were higher than reported for elite $(40.3 \pm 6.0 \mathrm{~cm})$ and county $(36.6 \pm 4.2 \mathrm{~cm})$ field hockey players in England [4]. Further, all class-year average vertical jump heights in this study were higher than regional $35 \pm 1 \mathrm{~cm}$ and club $29 \pm 1 \mathrm{~cm}$ female field hockey players in New Zealand [5]. Keogh et al. attributed the higher vertical jump in regional players to a higher level of lower body muscle power and an indicator of better play in field hockey [5]. The difference between the current athletes and past field hockey studies may be attributed to the methods used for the vertical jump. The prior studies did not use a countermovement jump, nor did they allow participants to swing their arms, which has been shown to result in higher vertical jump heights $[35,36]$. Field hockey players, both in this study and prior studies, had a lower reported vertical jump height than Division I soccer players [10,11,18]. Although soccer and field hockey require similar fitness levels, soccer requires jumping throughout games, whereas field hockey does not. This necessary game skill may be the reason for the differences in the jump heights between the two sports. Due to the number 
of improvements in vertical jump seen in the current study, this may indicate that the team's ability, specifically with regards to explosive quick movements, improved during the competitive season.

The Yo-Yo IR1 results conform to the hypothesis first-year athletes would have the lowest distance, and Yo-Yo IR1 distance would improve from pre to post season. The Yo-Yo IR1 distances by athletes in this study tended to fit within the context of other published studies of female field hockey players. Yo-Yo IR1 distances have shown to increase with both age and competition level [26]. Yo-Yo IR1 distances of sub-elite players in Australia were found to be $840 \pm 280 \mathrm{~m}$ for under 21 athletes (19.4 \pm 0.7 years) [37] and to increase to $1320 \pm 353 \mathrm{~m}$ for athletes aged $22.3 \pm 2.3$ years [38]. Yo-Yo IR1 distances of elite players in Canada ranged from $1068 \pm 220 \mathrm{~m}$ for under 17 athletes and increased to $1480 \pm 332 \mathrm{~m}$ for under 21 athletes [28]. Using consistent athlete level classifications from Schmitz et al., athletes in this study would fall at the amateur level, just below the sub-elite level [39]. Thus, the first-year athletes in this study having an average Yo-Yo IR1 distance lower than previous studies is reasonable. Further, the sophomore and junior athletes in this study having a higher Yo-Yo IR1 distance than the younger elite athletes, but lower than older sub-elite and comparably aged elite athletes was also expected. The average pre to post season gain of $19.7 \%$ for the current study is similar to the range of $12-28 \%$ improvement in Yo-Yo IR1 distances from multiple studies [26]. The large difference between the first-year average and the older athletes in this and previous studies indicates additional training or conditioning may be needed to bring new players to a higher level of fitness. The Yo-Yo IR1 test may be useful for coaches to determine if players are ready for the competitive season. First-year, sophomore, and junior athletes each received similar suggested summer workout routines. Sophomore and junior athletes also had previous collegiate level athletic training from spring; however, first-year athletes were not part of a collegiate level athletic training program prior to the beginning of fall pre season practice. The presence of a collegiate level spring training may explain the difference of Yo-Yo IR 1 distance for sophomore and junior athletes when compared to first-years. Future work examining longitudinal athlete development across the spring could account for these differences.

The largest gains in all measures, except vertical jump, were in the first-year similar to male DI football players [17]. The first-year is an important area of focus for strength and conditioning coaches. The athletes in the current study came in at a lower fitness level for all measures. These athletes may not have had the strength and conditioning regimen in high school that is necessary for competing at the Division I level. Although the first-year athletes improved vertical jump and Yo-Yo IR1 distance after the season, they were still not at sophomore and junior levels. All athletes on the team did not have equal exercise workloads, as game time contributors had, on average, two more high load workouts in games per week than developmental players. Developmental players were provided with optional off field workout plans for game days when they were not playing; however, NCAA rules make tracking and requiring those workouts problematic [7]. Playing time was lowest for first-years, which may be one reason why the post season Yo-Yo IR1 distance was still below the average pre season distance for sophomores and juniors. Steady improvement to bring first-year levels to sophomore and junior levels may occur in the off-season when all athletes have more consistent workload experiences.

There are limitations to this study. First, athletes were tracked for one competitive season. These results may not extrapolate to other seasons or other teams. Future work should follow athletes longitudinally through their collegiate career. The sample size is small, but comparable to other Division I field hockey teams. Roster sizes in the low twenties are common for Division I teams, typically with two to three goalkeepers, which may limit the power of the results from a single team. The most experienced members of the team, the seniors, were not included due to no post season data available. Once the competitive season is over, NCAA rules prohibit required athletically related activities, thus seniors whose playing career has ended can (and readily do) choose not to participate in post season testing, thus the reason for them not being included here. In the future, 
it would be advantageous to include all four class years in analysis. This would benefit younger players as they could track their development. Additionally, scheduling needs did not allow for a fasting period for measuring percent body fat; nonetheless, NIR does not require any specific subject preparation according to the manufacturer specifications. Finally, while nutritional guidance was provided the diet of subjects was not rigorously monitored across the season; therefore, alimentation could impact the results seen here. Therefore, it is possible this lack of fasting could lead to variability in percent body fat, and make it more challenging to compare to other work.

\section{Conclusions}

This study is the first to examine differences in anthropometric and fitness measures in Division 1 field hockey athletes. The largest gains in mass and percent body fat were seen in first-year athletes. Vertical jump improved for all first-years and sophomores. Only two junior athletes did not improve their jump height. The largest percent gain in Yo-Yo IR1 distance was seen in first-year athletes though sophomores had the overall best performance both before and after the season.

The density of the NCAA field hockey season (20 games in 14 weeks) creates an environment where student-athletes are training up to $20 \mathrm{~h}$ a week, with an average of two games per week, and only a single day off. Fitness measures, as well as speed and strength, can be built into tactical and technical training sessions without specific time and work spent on the former. This study seems to suggest this approach, as very little, if any time during the season was spent on specific activities designed to improve either vertical jump or Yo-Yo IR1 distance. Further, the results may warrant looking at the phases of the competitive year (pre season, season, spring training) as one phase, continuously moving towards speed, strength, and fitness. Such a continuous approach is less common as many coaches have previously used summer pre season to focus on endurance, the season to focus on tactical and technical aspects of the game, early spring to focus on building strength and explosiveness, and late spring to bridge the strength and endurance to game play. Also, coaches should continue to consider ways to encourage athletes who are not participating in games to consider optional, alternative, high intensity workouts, on or around game days, while being mindful of NCAA rules.

Coaches should be aware that first-year athletes may not be at the same level of conditioning as sophomores and juniors. Coaches should work specifically with the firstyear athletes during the season to monitor their fitness levels. Using the fitness metrics of vertical jump and Yo-Yo IR1 distance may be one method to determine the readiness of first-year athletes to handle the increased physical load of competition in college.

Supplementary Materials: The following are available online at https:/ / www.mdpi.com/article/10 .3390/app11178103/s1, DataSet S1: Data from study.

Author Contributions: Conceptualization, K.A.B., J.A.C. and R.C.S.; Methodology, K.A.B., J.A.C. and R.C.S.; Formal Analysis, K.A.B.; Investigation, J.A.C. and R.C.S.; Data Curation, K.A.B. and R.C.S.; Writing-Original Draft Preparation, K.A.B. and R.C.S.; Writing-Review \& Editing, K.A.B., J.A.C. and R.C.S.; Visualization, K.A.B.; Supervision, K.A.B., J.A.C. and R.C.S.; Project Administration, K.A.B., J.A.C. and R.C.S. All authors have read and agreed to the published version of the manuscript.

Funding: This research received no external funding.

Institutional Review Board Statement: The study was conducted according to the guidelines of the Declaration of Helsinki, and approved by the Institutional Review Board (or Ethics Committee) of Bucknell University (protocol code 1718-005, approved 28 July 2017).

Informed Consent Statement: Informed consent was obtained from all subjects involved in the study.

Data Availability Statement: The data presented in this study are openly available in Supplementary Materials.

Acknowledgments: The authors would like to thank assistant coaches Sam Carlino and Anna Wills, as well as strength and conditioning assistant Colleen Looney for assistance with data collection. 
Conflicts of Interest: The authors declare no conflict of interest.

\section{References}

1. Harry, K.; Booysen, M.J. Faster Heart Rate Recovery Correlates with High-Intensity Match Activity in Female Field Hockey Players-Training Implications. J. Strength Cond. Res. 2020, 34, 1150-1157. [CrossRef] [PubMed]

2. McGuinness, A.; Passmore, D.; Malone, S.; Collins, K. Peak Running Intensity of Elite Female Field Hockey Players during Competitive Match Play. J. Strength Cond. Res. 2020. [CrossRef]

3. The International Hockey Federation. The International Hockey Federation Rules of Hockey from 1 January 2017; The International Hockey Federation: Lausanne, Switzerland, 2016.

4. Reilly, T.; Bretherton, S. Multivariate Analysis of Fitness of Female Field Hockey Players. In Perspectives in Kinanthropometry; Day, J., Ed.; Human Kinetics: Champaign, IL, USA, 1986; pp. 135-142.

5. Keogh, J.W.L.; Weber, C.L.; Dalton, C.T. Evaluation of anthropometric, physiological, and skill-related tests for talent identification in female field hockey. Can. J. Appl. Physiol. 2003, 28, 397-409. [CrossRef]

6. Podgórski, T.; Pawlak, M. A half century of scientific research in field hockey. Hum. Mov. 2011, 12, 108-123. [CrossRef]

7. NCAA Academic and Membership Affairs Staff. 2017-2018 NCAA Division I Manual; NCAA: Indianapolis, IN, USA, 2017.

8. Harnish, C.R.; Bullock, G.; Hendrix, S.; Baumann, J. Physical, Performance, and Functional Movement Characteristics of Ncaa Division III Women's Soccer and Volleyball Players. ARC J. Res. Sports Med. 2017, 2, 27-33.

9. Vescovi, J.D.; Brown, T.D.; Murray, T.M. Positional characteristics of physical performance in Division I college female soccer players. J. Sports Med. Phys. Fit. 2006, 46, 221.

10. Risso, F.G.; Jalilvand, F.; Orjalo, A.J.; Moreno, M.R.; Davis, D.L.; Birmingham-Babauta, S.; Stokes, J.J.; Stage, A.A.; Liu, T.M.; Giuliano, D.V.; et al. Physiological characteristics of projected starters and non-starters in the field positions from a Division I women's soccer team. Int. J. Exerc. Sci. 2017, 10, 568-579. [PubMed]

11. Lockie, R.G.; Moreno, M.R.; Lazar, A.; Orjalo, A.J.; Giuliano, D.V.; Risso, F.G.; Davis, D.L.; Crelling, J.B.; Lockwood, J.R.; Jalilvand, F. The physical and athletic performance characteristics of Division I collegiate female soccer players by position. J. Strength Cond. Res. 2018, 32, 334-343. [CrossRef] [PubMed]

12. NCAA DI Women's Soccer Rankings-NCAA Women's Soccer RPI. Available online: https://www.ncaa.com/rankings/soccerwomen/d1/ncaa-womens-soccer-rpi (accessed on 12 June 2019).

13. NCAA DI Field Hockey Rankings-NCAA Field Hockey RPI. Available online: https://www.ncaa.com/rankings / fieldhockey/ d1/ncaa-field-hockey-rpi (accessed on 12 June 2019).

14. Andres, K. 2018 and 2019 NCAA Men's and Women's Soccer Rules; NCAA: Indianapolis, IN, USA, 2018.

15. Wassmer, D.J.; Mookerjee, S. A descriptive profile of elite US women's collegiate field hockey players. J. Sports Med. Phys. Fit. 2002, 42, 165-171.

16. Wade, S.M.; Pope, Z.C.; Simonson, S.R. How prepared are college freshmen athletes for the rigors of college strength and conditioning? A survey of college strength and conditioning coaches. J. Strength Cond. Res. 2014, 28, 2746-2753. [CrossRef]

17. Stodden, D.F.; Galitski, H.M. Longitudinal effects of a collegiate strength and conditioning program in American football. J. Strength Cond. Res. 2010, 24, 2300-2308. [CrossRef]

18. Lockie, R.G.; Stecyk, S.D.; Mock, S.A.; Crelling, J.B.; Lockwood, J.R.; Jalilvand, F. A cross-sectional analysis of the characteristics of Division I collegiate female soccer field players across year of eligibility. J. Aust. Strength Cond. 2016, 24, 6-15.

19. Stanforth, P.R.; Crim, B.N.; Stanforth, D.; Stults-Kolehmainen, M.A. Body composition changes among female NCAA division 1 athletes across the competitive season and over a multiyear time frame. J. Strength Cond. Res. 2014, 28, 300-307. [CrossRef] [PubMed]

20. Petko, M.; Hunter, G.R. Four-year changes in strength, power, and aerobic fitness in women college basketball players. Strength Cond. J. 1997, 19, 46-49. [CrossRef]

21. Hoffman, J.R.; Ratamess, N.A.; Kang, J. Performance changes during a college playing career in NCAA division III football athletes. J. Strength Cond. Res. 2011, 25, 2351-2357. [CrossRef] [PubMed]

22. Hunter, G.R.; Hilyer, J.; Forster, M.A. Changes in fitness during 4 years of intercollegiate basketball. J. Strength Cond. Res. 1993, 7, 26-29.

23. Fthenakis, Z.G.; Balaska, D.; Zafiropulos, V. Uncovering the FUTREX-6100XL prediction equation for the percentage body fat. J. Med. Eng. Technol. 2012, 36, 351-357. [CrossRef]

24. Moon, J.R.; Hull, H.R.; Tobkin, S.E.; Teramoto, M.; Karabulut, M.; Roberts, M.D.; Ryan, E.D.; Kim, S.J.; Dalbo, V.J.; Walter, A.A Percent body fat estimations in college women using field and laboratory methods: A three-compartment model approach. J. Int. Soc. Sports Nutr. 2007, 4, 16. [CrossRef]

25. Fukuda, D.H.; Wray, M.E.; Kendall, K.L.; Smith-Ryan, A.E.; Stout, J.R. Validity of near-infrared interactance (FUTREX 6100/XL) for estimating body fat percentage in elite rowers. Clin. Physiol. Funct. Imaging 2017, 37, 456-458. [CrossRef]

26. Bangsbo, J.; Iaia, F.M.; Krustrup, P. The Yo-Yo Intermittent Recovery Test. Sports Med. 2008, 38, 37-51. [CrossRef]

27. Krustrup, P.; Mohr, M.; Amstrup, T.; Rysgaard, T.; Johansen, J.; Steensberg, A.; Pedersen, P.K.; Bangsbo, J. The yo-yo intermittent recovery test: Physiological response, reliability, and validity. Med. Sci. Sports Exerc. 2003, 35, 697-705. [CrossRef]

28. Vescovi, J.D. Locomotor, heart-rate, and metabolic power characteristics of youth women's field hockey: Female athletes in motion (FAiM) study. Res. Q. Exerc. Sport 2016, 87, 68-77. [CrossRef] [PubMed] 
29. McFarland, I.T.; Dawes, J.J.; Elder, C.L.; Lockie, R.G. Relationship of two vertical jumping tests to sprint and change of direction speed among male and female collegiate soccer players. Sports 2016, 4, 11. [CrossRef]

30. Leard, J.S.; Cirillo, M.A.; Katsnelson, E.; Kimiatek, D.A.; Miller, T.W.; Trebincevic, K.; Garbalosa, J.C. Validity of two alternative systems for measuring vertical jump height. J. Strength Cond. Res. 2007, 21, 1296-1299.

31. Lakens, D. Calculating and reporting effect sizes to facilitate cumulative science: A practical primer for $t$-tests and ANOVAs. Front. Psychol. 2013, 4, 863. [CrossRef]

32. Portney, L.G.; Watkins, M.P. Foundations of Clinical Research: Applications to Practice; Prentice Hill Health: Upper Saddle River, NJ, USA, 2000.

33. Vella-Zarb, R.A.; Elgar, F.J. The 'freshman 5': A meta-analysis of weight gain in the freshman year of college. J. Am. Coll. Health 2009, 58, 161-166. [CrossRef] [PubMed]

34. Vadeboncoeur, C.; Townsend, N.; Foster, C. A meta-analysis of weight gain in first year university students: Is freshman 15 a myth? BMC Obes. 2015, 2, 22. [CrossRef]

35. Feltner, M.E.; Fraschetti, D.J.; Crisp, R.J. Upper extremity augmentation of lower extremity kinetics during countermovement vertical jumps. J. Sports Sci. 1999, 17, 449-466. [CrossRef]

36. Richter, A.; Räpple, S.; Kurz, G.; Schwameder, H. Countermovement jump in performance diagnostics: Use of the correct jumping technique. Eur. J. Sport Sci. 2012, 12, 231-237. [CrossRef]

37. Thomas, A.; Dawson, B.; Goodman, C. The yo-yo test: Reliability and association with a 20-m shuttle run and $\mathrm{VO}_{2 \mathrm{max}}$ Int. J. Sports Physiol. Perform. 2006, 1, 137-149. [CrossRef]

38. Heaney, N. The Effect of a 4 week aerobic interval training block using maximal aerobic speed as the intensity measure with elite female hockey players. J. Aust. Strength Cond. 2012, 20, 97-102.

39. Schmitz, B.; Pfeifer, C.; Kreitz, K.; Borowski, M.; Faldum, A.; Brand, S. The yo-yo intermittent tests: A systematic review and structured compendium of test results. Front. Physiol. 2018, 9, 870. [CrossRef] [PubMed] 